\title{
The Relationship Between Conscious and Unconscious Intentionality
}

\author{
RAAMY MAJEED \\ r.majeed@auckland.ac.nz \\ Philosophy (forthcoming)
}

\begin{abstract}
The contemporary view of the relationship between conscious and unconscious intentionality consists in two claims: (i) unconscious propositional attitudes represent the world the same way conscious ones do, and (ii) both sets of attitudes represent by having determinate propositional content. Crane (2017) has challenged both claims, proposing instead that unconscious propositional attitudes differ from conscious ones in being less determinate in nature. This paper aims to evaluate Crane's proposal. In particular, I make explicit and critique certain assumptions Crane makes in support of his asymmetry, and argue for a conditional claim: if Crane is right that unconscious intentional states are (relatively) indeterminate, this suggests that conscious intentional states are indeterminate in a similar fashion as well.
\end{abstract}

\section{Introduction}

What is the relationship between conscious and unconscious intentionality? According to the contemporary view, (i) unconscious propositional attitudes represent the world the same way conscious ones do, and (ii) both sets of attitudes represent by having determinate propositional content. Crane (2017) has recently challenged both claims, proposing instead that unconscious propositional attitudes differ from conscious ones in being less determinate in nature. 
With regards to this comparison, Crane's primary focus is the structure of unconscious psychological reality. Analytic philosophers on the whole don't tend to ask questions about the unconscious, let alone inquire into its intentional aspects. On the rare occasion when they have done so, they have tended to deny the existence of unconscious intentional states (e.g. Searle, 1992). The rest of us seem to assume that what goes for conscious intentionality also goes for that of the unconscious. Crane, drawing inspiration from Freud, prefers a different view: the unconscious comes with its own rules and principles. ${ }^{1}$ More specifically, and I now speak for Crane not Freud, the unconscious is holistic in nature, and its contents are far less determinate than those present in consciousness.

It is instructive to put this in Crane's own terminology. According to Crane, beliefs are always unconscious, and are to be contrasted with thoughts, which are always conscious. ${ }^{2}$ Moreover, Crane introduces the notion of a 'worldview', which consists of a subject's entire system of belief, i.e. their entire unconscious representation of the world. The crux of Crane's position is that a worldview 'can be less specific, coherent and determinate than ordinary psychological ascriptions often suggest' (2017, p. 2).

We do not find an argument for this view in Crane's paper. What we find, rather, is an explanation for why we have been misled into thinking that unconscious propositional attitudes represent the world in the same way conscious ones do. In summary:

1 This reading of Freud is due to Wollheim (1971). See also Freud (1953-1964).

2 Nothing hangs on this in the present context. If you disagree with Crane, you can simply substitute his claims about 'belief' for those about 'unconscious belief', and claims about 'thought' for those concerning 'conscious thought'. 
My hypothesis is that cognitive science, commonsense psychology and psychoanalysis all operate with a conception of the unconscious as something that has a causal structure which is modelled by the attributions of propositional content by the theorist or the therapist. In order for these attributions to provide a successful interpretation of the unconscious mind, there is no requirement that they correspond in any straightforward sense to individual inner states with determinate propositional contents. The same is true of the subject's own first-person reflections on their worldview, and on their unconscious motivations. (Crane 2017, pp. 18-19)

Investigations into the nature of intentionality tend to start with the assumption that at least some propositional attitude ascriptions are true. For example, consider the ascription, 'Zita believes that Freud lived in North London'. What would it take for this ascription to be true? Typically, we think propositional attitude ascriptions are made true by individual inner states with determinate contents. The ascription concerning Zita, then, is true just in case she actually has an inner state with the content $<$ Freud lived in North London $>$. Crane's insight is that such ascriptions, when concerning unconscious intentionality, can be true even if there are no individual mental states with determinate contents. That is, they can be true even if the structure of unconscious intentionality is far less determinate than these practices suggest.

This is no doubt a controversial position, but one to which I am, nevertheless, sympathetic. My contention is with the caveat. Why think the grounds for believing that unconscious intentional states are indeterminate stop at the level just below consciousness? Put another way, if unconscious intentional states are (relatively) 
indeterminate, why aren't conscious intentional states likewise indeterminate? This paper aims to address this question.

In what follows, I tease out certain key assumptions Crane makes in support of his proposal. First, I argue that Crane's claim that unconscious intentional states are (relatively) indeterminate rests on adopting a version of interpretationism, which holds that the nature of unconscious belief can be understood in terms of interpretation. Here I also make the point that since Crane doesn't adopt interpretationism wholesale, this allows him room to consider conscious intentional states, e.g. thoughts, as still being determinate (§2). I then turn to why Crane thinks thoughts are, as a matter of fact, determinate. I argue that implicit in Crane's reasoning must be a controversial form of sententialism, which holds that we (mostly) think by tokening sentences in a natural language (§3). Finally, I go on to raise some doubts about this form of sententialism by way of challenging Crane's proposed asymmetry (§4). I conclude that if Crane is right that unconscious intentional states are (relatively) indeterminate, this suggests that conscious intentional states are indeterminate in a similar fashion as well.

\section{Interpretationism about belief}

Precisely in what sense are (unconscious) beliefs supposed to be indeterminate? According to Crane, 'A lot of what we believe is incomplete, partial, confused, and even 
contradictory' (2017, p. 11). Crane takes this as a datum; one that needs explaining. ${ }^{3}$ But before we get to an explanation, I think it also calls for clarification.

Some insight into what Crane means by unconscious states being 'indeterminate' can be found by considering discussions of indeterminacy in the context of interpretation. (This isn't a stretch because interpretation, as we shall see shortly, is central to Crane's proposal). To begin, following Child (1994), we can make a distinction between two kinds of indeterminacy. Both problematise the standard assumption that propositional attitudes have determinate contents. But they do so in different ways. The first better speaks to the notion of incomplete or partially formed beliefs. Here the problem is with ascribing 'fullblown' propositional attitudes to subjects owing to the context-dependent nature of mental descriptions, which result in vague or borderline cases. This is best seen by example:

Consider, for instance, a child who is learning to use the word 'sister', and who has reached a stage where she knows that 'sister' applies to her own sisters, but does not realise that someone can be a sister without being a sister of hers. (Child, 1994, p. 69)

Such cases, according to Child, are borderlines cases where it is indeterminate whether subjects have the relevant beliefs, e.g. that the child believes that Katy is her sister. Crucially, such indeterminacy arises not because there is no fact of the matter about which competing ascriptions best describe the subject's propositional attitudes, but because 'the

3 Crane argues that this datum is best explained by the view that treats propositional attitude ascriptions as (mere) models, as opposed to the standard picture which takes such ascriptions to coincide with individual belief states with determinate content. 
facts of the matter are not reportable by simple ascriptions of the form ' $S$ believes that $p^{\prime \prime}($ p. 70).

The second type of indeterminacy, by contrast, arises precisely because there is no fact of the matter about which competing ascriptions best describe a subject's propositional attitudes. This is the indeterminacy of interpretation, owing to Davidson (1974) and developed further by Dennett (1991). ${ }^{4}$ As Child reads Davidson, this kind of indeterminacy, ultimately, is a product of different methods of interpretation being empirically equivalent. In brief, given that an agent's choice is determined jointly by their beliefs and desires, there will be numerous distinct ascriptions of beliefs and desires which will equally explain their choice. Some of these ascriptions can be eliminated when we require ascriptions to count for not just a single choice but a whole host of data. Nevertheless, it is possible that not all such ascriptions can be thus eliminated, in which case there will be competing propositional attitude ascriptions that prove empirically equivalent. ${ }^{5}$

What we have yet to explain is why an empirical equivalence results in there being no fact of the matter of which ascriptions are correct. One could insist, for instance, that there is an individual belief state, with determinate propositional content, which actually explains the subject's choice - regardless of whether their dispositional profile underdetermines which belief we should ascribe to them from a set of competing beliefs.

\footnotetext{
4 Note: this is not to be confused with Quine's (1960) indeterminacy of translation.

${ }^{5}$ For Crane, the holism of the intentional 'guarantees' that we can't have one-to-one mappings between individual beliefs and their dispositional profiles (p. 13).
} 
The key assumption for both Davidson and Dennett is interpretationism. According to such an interpretationism:

all there is to being a true believer is being a system whose behaviour is reliably predictable via the intentional strategy, and hence all there is to really and truly believing that $p$ (for any proposition $p$ ) is being an intentional system for which $p$ occurs as a belief in the best (most predictive) interpretation. (Dennett, 1987, p. 29)

The strategy in question is the intentional stance, where we treat a subject as a rational agent who has beliefs and desires, and whose actions can be explained on the basis of their having these mental states. Interpretationism tells us that our being able to adopt this strategy to successfully predict the behaviour of a subject is constitutive of this subject having the relevant beliefs and desires.

The commitments of interpretationism concerning belief, thus understood, do not entail the indeterminacy of interpretation. However, they do so when coupled with the aforementioned claim about empirical equivalence. If all there is for a belief ascription to be true is for that ascription to be the most predictive ascription that could be assigned by an interpreter, and if there are distinct belief ascriptions which are empirically equivalent, and ergo equally predictive, there will be no fact of the matter about which belief, amongst a set of competing beliefs, is actually had by the agent. The difference between Davidson and Dennett is that Dennett thinks this framework allows for an even more radical form of indeterminacy, where distinct empirically equivalent methods of interpretation may sometimes ascribe beliefs with conflicting propositional contents. 
Crane's datum, i.e. that unconscious beliefs can be 'incomplete, partial, confused, and even contradictory', allows for both forms of indeterminacy specified by Child. His main focus, and the kind of indeterminacy peculiar to the unconscious, however, is the second. That is to say the indeterminacy of our worldview, which Crane takes as a datum, primarily has to do with an absence of any facts that determine which competing, even conflicting, ascriptions best describe a subject's worldview. In this way, we see that interpretationism is crucial to understanding Crane's proposed worldview.

But that is not all. Interpretationism also helps explain why conscious intentionality mightn't suffer from the same kind of indeterminacy. In brief, interpretationism for Crane doesn't hold true for all forms of intentionality.His example is the intentional activity of interpretation itself: 'For one thing, interpretation itself is a mental activity, so we cannot expect all intentionality to be explained in terms of interpretation ... Conscious acts of interpretation do not require interpretation to give them their content' (2007, pp. 14-15). If that's right, i.e. if conscious intentional states gain their contents not by interpretation but through some other means, this tells us that it might be possible for them to have determinate contents - even if the competing ascriptions that best describe them prove to be empirically equivalent. So the fact that interpretation doesn't apply to conscious intentional states explains why it might be possible for such states to be determinate. Let us now look at why they must be determinate on Crane's picture.

\section{Sententialism about thought}


According to Crane, conscious thoughts are determinate in a way (unconscious) beliefs are not. This is supposed to hold true for thoughts we have about our beliefs as well. The idea, roughly, is as follows.

According to the contemporary view, when we introspect what we believe, we bring to conscious awareness the determinate contents of these beliefs, whereas when we make up our minds, we impose a certain determinate structure on the contents of our indeterminate mental states and thereby make them determinate. Crane seeks to collapse this distinction. As we saw, the contents of unconscious beliefs are not determinate propositional contents waiting to be discovered. Rather, unconscious intentionality tends to be indeterminate, and what we do when we introspect is make a conscious judgement as to the contents of our beliefs, which in turn imposes on them a certain determinate structure. Introspecting our beliefs, then, is akin to making up our minds.

One way to unpack this idea is to suppose that the act of judgement involves picking out a single belief-content from the set of competing contents we may ascribe to a subject's belief - even when the subject is oneself. For example, it may be indeterminate whether I truly believe that the Prime Minster is clumsy. However, introspection involves considering an array of belief contents I may ascribe to myself (e.g. $<$ he is $>,<$ he isn't $>$ ), which is typically followed by a conscious judgement as to which belief content I should ascribe to myself. In this way, though the contents of beliefs themselves may be indeterminate, our conscious awareness of the content of any given belief involves determinate content. Another way of making this point is to say that when we introspect our beliefs, we in effect interpret them using certain determinate propositional contents. As Crane puts it, the 'central phenomenon here is interpretation. To model an aspect of a 
worldview with a proposition is to interpret it' (2017, p. 14). For Crane, this holds true whether we are interpreting our own worldview or the worldview of others.

But why does making a conscious judgement assign a fixed determinate content to a belief? For instance, why can't judgements themselves have indeterminate content? According to Crane, an answer lies in the way conscious judgements involve language:

The clearest way in which the content of a worldview can become the content of a conscious judgement is when one says something, either aloud or to oneself ... When we use words to express our beliefs, often by uttering a sentence, we impose an order on what we think which can then make our subsequent dispositions more determinate. (Crane, 2017, p. 14)

The process of discovering what you believe, like that of making up your mind, involves articulating the contents of your beliefs in language, which inevitably ascribes determinate contents to these beliefs. As Dennett puts it, 'our linguistic environment is forever forcing us to give - or concede - precise verbal expression to convictions that lack the hard edges verbalization endows them with' (1987, p. 21).

So far we have been considering thoughts we have about what we believe. But the same is supposed to hold true for thoughts which don't bear on any of our beliefs. In most cases, to entertain a thought in consciousness, according to Crane, is to entertain a mental representation via the use of language, which inevitably results in our thoughts having determinate content. At this point it is worth being clear on the scope of Crane's proposal. 
He doesn't just assume that some of our thoughts are more determinate than our beliefs, but that thoughts, in general, are more determinate than our beliefs. ${ }^{6}$

This is also precisely the point at which the proposal becomes questionable. Crane's proposed asymmetry between conscious and unconscious intentionality seems to be grounded in the not entirely uncontroversial premise that all, if not most, conscious thought is linguistic. Crane considers this explicitly in earlier work: 'Maybe the 'vehicle' of the content of a conscious thought is words running through your mind' (Crane, 2013a, p. 171). ${ }^{7}$ But this is something that needs to be more than mere speculation for the present purpose. A full-blown critique of the contemporary conception of the relationship between conscious and unconscious intentionality, as it turns out, rests on this very premise. ${ }^{8}$

To clarify, I don't think there is enough textual evidence to establish that Crane actually assumes that all, if not most, thoughts are linguistic. My claim, rather, is that Crane must assume that most thoughts are linguistic because otherwise he doesn't have support for his proposed asymmetry. Put another way, it remains unclear whether Crane

${ }^{6}$ Crane's actual conclusion is even bolder, i.e. that there is a significant difference between the structures of unconscious and conscious intentionality. To establish this conclusion, Crane must hold that linguistic representation is not just a feature of our thoughts, but of all, if not most of, our conscious intentional states - be they thoughts, judgements, hopes, desires, imaginings, and so on. For the sake of simplicity, in this paper I will restrict my discussion to thoughts.

7 Likewise, elsewhere Crane notes that 'often we think in words' (2016, p. 15), which shows a sympathy towards, though not a full-blown commitment to, the view that thinking is typically linguistic in nature

8 The are other ways to maintain the asymmetry which Crane does not consider. E.g. you could suppose, à la Pitt (2004), that phenomenal character alone suffices to confer conscious thoughts their determinate character. See Kriegel (2014) for a survey, and Vicente and Jorba (2019) for a response. It is worth noting that Vicente and Jorba's response is motivated by a view concerning linguistic thinking similar to Crane's. 
actually makes this assumption. But I think it is reasonable to suggest that he must assume it given that all he says by way of supporting the view that conscious states are more determinate than unconscious ones consists of the aforementioned passages; ones where the determine nature of conscious states is attributed to our use of words. ${ }^{9}$

It is also important to clarify here the distinction between mental representation which is linguistic in form and that which is propositional. At minimum, for a representation to have propositional content is for it to have the kind of content which can be true or false. The contents of sentences are often propositional in nature. ${ }^{10}$ But not all propositional content is, arguably, sentential or linguistic in form. The content of a map can, arguably, be propositional in nature. For instance, the Sydney map represents Bondi Beach as being to the southeast of the Harbour Bridge. On this basis, it can be said to have the propositional content $<$ Bondi Beach is to the southeast of the Harbour Bridge $>.11$ The point of contention is not whether thoughts are propositional, but whether they are linguistic. In particular, whether they involve sentences, composed of words.

The view that thoughts are sentences (or sentence-like) is a version of sententialism: roughly, the view that mental representation is linguistic in nature. ${ }^{12}$ Sententialists divide

\footnotetext{
${ }^{9} \mathrm{I}$ am grateful to an anonymous referee for raising this concern.

10 Not all sentences are propositional, e.g. sentences which express imperatives aren't propositional because they are neither true nor false.

${ }^{11}$ Whether the same could be said for the content of pictures is a point of contention. Crane (2009) denies that pictures have propositional content on grounds that propositions, unlike the contents of pictures, can be asserted or denied, and can stand in logical relations. See Grzankowski (2015) and Camp (2018) for a reply.

12 Advocates of this view include Sellars (1956), Harman (1973), Fodor (1975), Gauker (1994), Carruthers (1996), and Devitt and Sterelny (1999).
} 
into two. Those who accept the language of thought hypothesis, as championed by Harman (1973) and Fodor (1975), claim that our thoughts are sentences in aa non-natural language or mentalese. The rest assume that our thoughts aren sentences in a natural language. The point for us is that 'the hard edge of determinacy' conferred to our thoughts for both Dennett and Crane is an inevitable consequence of the use of natural language; it is the use of words that 'impose an order on what we think' (Crane, 2017, p. 14). Consequently, the topic under investigation is the view according to which when you token a thought that $p$, you token a sentence in some natural language that means $p$. As an English speaker, when I think of my friend that he likes anything sweet, I token the English sentence 'he likes anything sweet'. If I spoke Polish, I might token the Polish sentence, 'On lubi wszystko, co jest słodkie', and so on.13

Both forms of sententialism are controversial, but both forms of it are also very much live options. Since it is the natural language version of sententialism which is integral to Crane's proposal, we can put the plausibility of the language of thought hypothesis aside. The obvious question is, How plausible is the natural language version of sententialism? This is an important question, one which is directly relevant for our purposes. However, we should be careful to make a distinction between the natural language version of sententialism, as commonly understood, and the more literal reading

\footnotetext{
${ }^{13}$ It is not obvious why Crane focusses on the natural language version of the language of thought, as a mental language, à la Fodor, would seem to possess the sorts of discrete symbols that could also render thoughts determinate. I would like to leave this as an open possibility alongside other ways thoughts could be determinate, e.g. via their phenomenal profiles. I suspect Crane himself doesn't entertain this possibility because he is sceptical that this version of the language of thought hypothesis is true on grounds that, for an empirically testable hypothesis, we still lack any empirical basis to accept it.
} 
of it, which Crane needs to support his asymmetry. In this way, we see that there is another question even more relevant for our purposes, one concerning the plausibility of this literal version.

\section{Thinking in words}

To recap, sententialism comes in many forms, but the asymmetry between (unconscious) belief and (conscious) thought rests on a very particular kind of sententialism, one that presupposes that thoughts are (predominantly) sentences in a natural language. More specifically, since it is the use of words which gives thoughts their determinate contents, the kind of sententialism in question must presuppose that words literally figure in thought. The problem with this view, I argue, is that it is insufficiently motivated.

There are really two aspects to this problem. First, advocates of the natural language version of sententialism don't tend to accept that we literally think in words. Second, even if they did, there is insufficient evidence for this claim. Consider the first issue. In practice, sententialists find it useful to model thought via language. Kukla and Lance, for instance, observe that while it is common to refer to thought as inner speech, 'Most philosophers readily admit that thought is not literally inner speech, but find it unproblematic to extend the linguistic toolbox inwards, as it were' $\left(2016\right.$, p. 81). ${ }^{14}$ Moreover, to the extent that this modelling presupposes a literal isormophism between language and thought, this tends to be assumed at the level of structure. Some have gone so far as to suggest that this is all we can assume:

\footnotetext{
14 Their original target is Sellars's (1956) project of modelling communicative thought on the basis of inner speech.
} 
What precisely would be required for a mentalese sentence to be a sentence of, say, English? Clearly it must consist of English words in an English structure. We think sense can be made of it having an English structure. But what sense can be made of it consisting of English words? What would make a mental word English? We doubt that there is a theoretically interesting answer.' (Devitt and Sterelny, 1999, p.

Sententialists, then, don't tend to assume that we literally think in words. But perhaps they could. What's so bad about assuming that we literally think in words anyway?

One answer, as suggested by Devitt and Sterelny, is that it is nonsensical. I find this way of raising scepticism about the literal reading too quick. This reading may seem far fetched, even empirically intractable, but this isn't the same thing as saying that it is nonsensical. Unfortunately Devitt and Sterelny don't elaborate on the matter. As far as I can tell, the nonsensicality charge is originally due to Ryle (1958). To my mind, Ryle doesn't do a very thorough job of justifying this charge either, but it is instructive to look at Ryle for it helps us see more clearly what's really wrong with this idea.

An initial reading of Ryle proves puzzling. On the one hand, Ryle is sceptical of the idea that we think in words: 'I want to deny that it even makes sense to ask, in the general case, what special sort or sorts of things we think in' (p. 13). However, on the other hand, Ryle also grants that thinking on occasion 'requires the inward or outward production of words or phrases (p. 10). For instance, he believes this to be the case when we think about what to say in a poem or a post-dinner speech. But if thinking can involve the inward 
production of words, why is it unintelligible to suppose that we normally think in words? Isn't this, in effect, the same thing?

A way to reconcile this tension is to make a distinction between thinking in words and thinking which involves words. It may turn out that there are forms of thinking which plausibly do involve words, e.g. when we try to articulate to ourselves what to say in a speech, but this shouldn't be taken to entail that we normally think in words - where words are the concrete vehicles of thought, i.e. roughly, the 'way' those contents are represented; the way they are stored. ${ }^{15}$ Ryle, I take it, accepts that thoughts can involve words. His scepticism, then, is really about whether it makes sense to talk of the vehicles of thought.

I say Ryle's scepticism is poorly defended because like Devitt and Sterelny, Ryle doesn't really provide us with any reasons as to why it is nonsensical to suppose that we think in words. ${ }^{16}$ But the aforementioned distinction helps us see what's really wrong with this idea. Most people I suspect are sympathetic to this notion because it introspectively seems to us as if we think in words. In other words, the main motivation for the literal version of sententialism is introspective evidence. The trouble is, our distinction shows this evidence to also be deceptively weak. In brief, introspection suggests that thought (somehow) involves words or sentences in a natural language. This much we can take for

15 E.g. consider a typical non-smoking sign, i.e. a drawing of a cigarette with a line across it, and a translation of it in English. Both have the same content, $<$ Do not smoke $>$, but the vehicles of representation are distinct: one is pictorial, the other is linguistic. See Crane (2013b).

16 When Ryle does comment on the matter, he only goes so far as to argue that our typical examples of thinking using words, e.g. say in English vs. French, don't really suffice to explain the sense in which we 'think in' words. In short, he thinks there are better explanations of such examples on offer than the one suggested by sententialism. Also see Harman (1973, §8). 
granted. But does it suggest that we think in words? Or does it merely suggest that thinking involves words? Introspective evidence itself doesn't seem to settle the issue.

A similar point has also been made by Machery (2005) in his critique of the introspective argument for sententialism. ${ }^{17}$ Machery begins by observing the distinction between the content and the vehicle of thought. The content is what the thought is about, whereas the vehicle is the way the content of that thought is represented, i.e. whether it is linguistic, imagistic etc. Machery argues that once we make this distinction, it is hard to see how we can have introspective grounds to accept sententialism because introspection only reveals the contents of thought, not its vehicles. For instance, I can introspectively know what I am thinking, but I don't seem to introspectively be able to also know the vehicles by which I can think these thoughts. Of course, the fact that it (sometimes) introspectively seems to us that we think in words needs to be accounted for, and Machery does so by suggesting that such seemings are really due to the fact that introspection also reveals the contents of auditory and articulatory images. We need not consider the matter settled. It suffices to note that the main source of evidence for the literal reading of sententialism, i.e. introspective evidence, is at best highly contestable.

In summary, the literal reading of sententalism is insufficiently motivated. It doesn't seem to be a view actually defended by sententialists. What's more, it doesn't seem to be a view that could be adequately defended either; at least not on introspective grounds. The problem for Crane is that he must rely on the literal reading, viz. that we actually think in words, to maintain the asymmetry between conscious and unconscious intentionality.

17 Machery's target is the version of sententialism defended by Carruthers (1996). For our purposes, we need not take a stand on whether this critique bears fruit. The crucial point is that it is an especially apt critique of the literal version of sententialism under consideration here. 
Here we find such a sententialism to be problematic, and ergo with it the alleged asymmetry.

Here it would be remiss not to stress, once again, that Crane doesn't actually commit to sententialism wholesale. Rather, the connection we find to the view in his work is (i) an assertion that we often think in words, (ii) speculation that the vehicles of conscious thought-contents are words running through our minds, and (iii) the idea that the clearest way thoughts get to be determinate is through their articulation in words. It is, therefore, entirely consistent with someone of Crane's persuasion to insist that some thinking could outstrip thinking in words. Some of it could, say, be imagistic or even numeric. What should we make of this possibility?18

I think this is a genuine possibility on Crane's view, but I don't think it helps defend the asymmetry. In fact, if anything, it is a hindrance. The issue of whether it is a hindrance hangs on whether we read Crane as proposing an asymmetry which is categorical. If there is supposed to be a sharp, definitive divide between conscious and unconscious intentionality vis-a-vis their determinacy, and conscious thoughts being articulated in words is what justifies this asymmetry, then the existence of non-linguistic forms of thinking would put pressure on the idea that all conscious intentional states are determinate. So counterexamples to sententialism, rather than being helpful, would actually pose a challenge to Crane.

However, I don't think this is Crane's position. A better reading has it that the difference between conscious and unconscious intentionality is really a matter of degree. In particular, unconscious intentional states, i.e the states which make up a subject's

\footnotetext{
${ }^{18}$ I am grateful to an anonymous referee for this journal for raising this concern.
} 
'worldview' are said to be 'less specific, coherent and determinate' than we typically assume $(2017$, p. 3). If that's right, the existence of non-linguistic forms of thinking wouldn't really pose a problem for Crane. That is, he could still hold that most thoughts are linguistic in order to justify his asymmetry.

But note that this more nuanced reading does nothing to address my worry; that when thinking is said to be linguistic on Crane's picture, he must assume the implausible and unmotivated literal reading. To elaborate, the problem with Crane's proposal isn't that he assumes a full-blown version of sententialism, one that takes all thinking to be linguistic. The problem, rather, is that to the extent to which he assumes that thinking is linguistic, he must assume that we literally think words - a view I have argued is insufficiently motivated. To my mind, a better response to this worry would be to offer an altogether different, and less contentious, account of what makes conscious thoughts determinate.

This is not the place to explore all the other ways thoughts could turn out determinate. However, to end, let us consider one idea that doesn't take us too far from the one we have considered thus far. That is, conscious intentional states are determinate because words form the contents, as opposed to the vehicles, of conscious thought. This would still capture one of Crane's key ideas, namely (iii), even though it won't capture (i) and (ii). Moreover, I also think there is a case to be made that a lot of thoughts involve words in this sense. For example, when I judge that the painting before me reminds me of a painting by the artist Lucian Freud, I seem to think this to myself in words. It strikes me that this is why our thoughts seem determinate; when we try to introspect our thoughts, it 
often seems as if we catch ourselves thinking in words. But the question is, can this be true of our thoughts in general?

This is a thorny issue to which I won't pretend to give a decisive answer here. It partly depends on whether we adopt an inclusive or restrictive notion of thought. Kukla and Lance, for instance, operate on an inclusive notion when they ask to consider 'the regular flow of thought-day dreams, minor arithmetic calculations, the fleeting worry that a cockroach will come closer...' (p. 93). These sorts of conscious intentional states needn't take shape in the form of auditory or articulatory imagery. If there are enough thoughts like this, and if thoughts are determinate due to their linguistic contents, we once again forgo our rationale for supposing that conscious thoughts are more determinate than unconscious beliefs. Of course, some thoughts would still be determinate on such an account. But this would be a far cry from the sort of widespread asymmetry assumed in Crane's picture.

And what if we adopt a more restricted notion? If paradigm examples of thought instead are things like judgements, opinions, inner speech — all things which tend to have linguistic content - then Crane's picture, that (conscious) thoughts are more determinate than our (unconscious) beliefs, becomes more plausible. But one major difficulty with adopting a more restricted notion is how to rule out things like daydreams, arithmetic calculations and worries from counting as species of thought. This is not a trivial task for to claim that they aren't thoughts because they aren't linguistic, in this context, would be to beg the question. What's more, there is a whole range of thinking which doesn't seem to require any words. For example, Harman asks us to consider 'a chess-player trying to frame a strategy, a mechanic trying to decide what is wrong with the motor of a car, or an 
an artist thinking whether to apply a dab of paint at a particular spot on canvas' (1973, p. 84). According to Harman, these are all instances of thinking which don't involve words. I think that's right. The diversity of the sorts of occurrences we typically count as thinking dampens the hope for a restrictive notion which would deliver the verdict that most thoughts have words as their contents. Consequently, for the time being, we can note that this way of supporting Crane's view remains at best speculative. The take-home message, then, remains the same: within the context of what Crane claims about the indeterminate nature of our unconscious beliefs, a problem-free account of what makes most of our thoughts determinate is lacking on his picture.

\section{Conclusion}

There is much to like about Crane's paper. In particular, I think he is right to point out that the widespread practice of ascribing propositional contents to unconscious beliefs is plausibly understood as a form of modelling, one which might mask an underlying indeterminate nature. But I think a similar point can also be made with regards to how we understand conscious thought. To talk of thoughts as linguistic entities is also plausibly understood as a form of modelling which may conceal an indeterminate nature.

Crane, however, claims that there is an asymmetry between conscious and unconscious intentionality. I have argued that this asymmetry rests on two assumptions: interpretationism about belief and sententialism about thought. The first assumption helps explain why Crane thinks beliefs are indeterminate, and in a way which still allows for thoughts to be determinate. Furthermore, the second clarifies why he must think most 
thoughts are, as a matter of fact, determinate. In short, thinking in words always yields thoughts with determinate contents.

In this paper, we have found the second of these assumptions to be insufficiently motivated. One lesson form this is that Crane simply doesn't go far enough. That is, if he is right about unconscious intentional states being (relatively) indeterminate, this suggests that conscious intentional states are indeterminate in a similar manner as well. This, in effect, is to side with one aspect of the contemporary view, the part which assumes that conscious and unconscious intentionality is isomorphic. But crucially, this isomorphism is preserved not for the reasons we originally thought. The structure of psychological reality, both conscious and unconscious, it would appear, is far less determinate than we ever imagined.

\section{References}

- Elisabeth Camp, 'Why Maps are Not Propositional'. In Alex Grzankowski and Michelle Montague (eds.), Non-Propositional Intentionality (Oxford: Oxford University Press, 2018).

- Peter Carruthers, Language, Thought, and Consciousness (Cambridge: Cambridge University Press, 1996).

- William Child, Causality, Interpretation, and the Mind (Oxford: Oxford University Press, 1994).

- Tim Crane, Elements of Mind: An Introduction to the Philosophy of Mind (Oxford: Oxford University Press, 2001). 
- Tim Crane, 'Is Perception a Propositional Attitude?' Philosophical Quarterly 59 (2009), 452-469.

- Tim Crane, 'Unconscious Belief and Conscious Thought'. In Uriah Kriegel (ed.), Phenomenal Intentionality, (Oxford: Oxford University Press, 2013a) 156-174.

- Tim Crane, 'The Given'. In Joseph K. Schear (ed.), Mind, Reason and Being-in-the-World: the McDowell-Dreyfus Debate, (London: Routledge, 2013b) 229-249.

- Tim Crane, The Mechanical Mind: A Philosophical Introduction to Minds, Machines and Mental Representation (Third Edition) (London: Routledge, 2016).

- Tim Crane, 'The Unity of Unconsciousness', Proceedings of the Aristotelian Society 117 (2017), 1-21.

- Michael Devitt and Kim Sterelny, Language and Reality: An Introduction to the Philosophy of Language (Cambridge, Massachusetts: MIT Press, 1999).

- Donald Davidson, ‘Radical Interpretation'. Dialectica 27 (1972), 314-328.

- Daniel C. Dennett, The Intentional Stance. (Cambridge, Massachusetts and London: MIT Press, 1987).

- Daniel C. Dennett, 'Real Patterns'. Journal of Philosophy 88 (1991), 27-51.

- Jerry A. Fodor, The Language of Thought. (Cambridge, Massachusetts: Harvard University Press, 1975).

- Sigmund Freud, The Standard Edition of the Complete Psychological Works of Sigmund Freud (James Strachey and Anna Freud eds.), 24 vols. (London: The Hogarth Press, 19531964).

- Christopher Gauker, Thinking Out Loud: An Essay on the Relation Between Thought and Language (Princeton: Princeton University Press, 1994). 
- Alex Grzankowski, 'Pictures Have Propositional Content', Review of Philosophy and Psychology 6 (2015), 151-163.

- Gilbert Harman, Thought (Princeton: Princeton University Press, 1973).

- Uriah Kriegel, 'The Phenomenal Intentionality Research Program'. In Uriah Kriegel (ed.), Phenomenal Intentionality, (New York: Oxford University Press, 2014) 1-27.

- Rebecca Kukla and Mark Lance, 'Speaking and Thinking'. In James R. O'Shea (ed.), Sellars E his Legacy, (Oxford: Oxford University Press, 2016), 81—99.

- Edouard Machery, 'You Don't Know How You Think: Introspection and Language of Thought', British Journal for the Philosophy of Science 56 (2005), 469-485.

- David Pitt, 'The Phenomenology of Cognition or What Is It Like To Think That P?' Philosophy and Phenomenological Research 69 (2004), 1-36.

- Willard Van Orman Quine, Word and Object (Cambridge, Massachusetts and London: MIT Press, 1960).

- Gilbert Ryle, 'A Puzzling Element in the Notion of Thinking'. Proceedings of the British Academy Vol. XLIV (1958). Reprinted in P. F. Strawson (ed.) Studies in the Philosophy of Thought and Action (London and New York: Oxford University Press, 1968).

- Wilfrid Sellars, 'Empiricism and the Philosophy of Mind'. Minnesota Studies in the Philosophy of Science 1 (1956), 253-329. Reprinted as Empiricism and the Philosophy of Mind, (Cambridge and London: Harvard University Press, 1997).

- Augustín Vicente and Marta Jorba, 'The Linguistic Determination of Conscious Thought Contents'. Nous 53 (2019), 737-759.

- Richard Wollheim, Freud (London: Fontana/Collins, 1971). 